\title{
Rock-fill Dam Construction Quality Evaluation Based on Combination Model
}

\author{
Fei Wang ${ }^{1, a}$, Qiangguo Jin ${ }^{2, b}$, Denghua Zhong ${ }^{1, c}$, and Binping $\mathrm{Wu}^{1, \mathrm{~d}}$ \\ ${ }^{1}$ State Key Laboratory of Hydraulic Engineering Simulation and Safety, Tianjin University, Tianjin, \\ 300072, China \\ ${ }^{2}$ School of Computer Software, Tianjin University, Tianjin, 300072, China

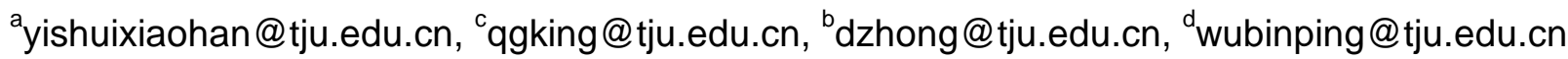

\begin{abstract}
Keywords: rock-fill dam; combination model; compaction; quality evaluation
Abstract: Rock-fill dam compaction quality depends on compaction parameters and material parameters. Although it is difficult to gain material sources parameters at any dam surface location, the real-time quality monitoring technology of rock-fill dam construction provides for gaining compaction parameters of any surface location. Based on test pit data and real-time data, establish the combination model connecting adaptive network-based fuzzy inference system and improved back propagation neural network, and realize the nonlinear mapping relationship between compaction parameters and construction quality.-The predicting accuracy of the combination model is higher than single adaptive network-based fuzzy inference system or improved back propagation neural network through model testing. Finally combination model is applied to forecast some dam surface dry density.
\end{abstract}

\section{INTRODUCTION}

The key to ensure rock-fill dam construction quality and operation safety is strengthening rolling parameters in the processing of construction control. Rock-fill dam construction quality evaluation is mainly based on the control of roller compaction parameters and the dry density of test pit. And it is given priority to with the parameters controlling construction processing. LIU et al. study the relationship between the parameters and the compaction quality using multiple regression model and artificial neural network, establish the nonlinear mapping relations, and put forward the rolling quality evaluation process for whole dam surface. [1]

In the aspect of combination model, J.M.BATES and C.W.J.GRANGER raise that combination model may make full use of the model information to improve the accuracy by connecting model through weights.[2] Robert R.ANDRAWIS adopts combination model to forecast the ATM cash competition, which results show that the combination model has higher prediction accuracy and stability than any single chosen model. [3] In the field of water resources and hydropower engineering, combination model has been applied to forecast the dam deformation successfully, which provides practical reference for compaction quality evaluation. [4] So it still needs further research.

Meanwhile the application of real-time monitoring system can improve the compaction quality control efficiency obviously, and provide conditions for dam surface evaluation.

\section{COMPACTION QUALITY INFLUENCE FACTORS ANALYSIS}

The factors affecting rock-fill dam surface compaction quality includes the filling materials, environment, machines and construction method, etc. in common. The compaction quality is measured by the dry density obtained by pit test at end of the surface rolling, which is also compared with the max day density at the same pit, called compactness. The material parameters including the moisture content, different size content are gained along with pit testing. So the influence factors of dam surface compaction quality can be summarized as material sources parameters and compaction parameters. [5] While in the case of actual project conditions, the number of the material data is limited. The sampling material parameters data based on limited data cannot represent the actual real material resource 
parameters space distribution. In order to guarantee the authenticity of data and prevent distortion, this study does not take the effect of material sources into consideration especially.

For the control in the event of rock-fill dam construction, ZHONG et al. develop the real-time monitoring technology, achieving the real-time monitoring of rolling speed, rolling passes and compacted thickness. [6, 7] This system aims thickness and rolling passes rate as the main indicators of compaction results. Compared with tradition control methods, this system greatly reduces the human factors interference on construction process.

The compaction parameters have the characteristic of real-time, and can be statistical analysis to gain at any surface location. Rock-fill dam real-time quality monitoring system controls the compaction parameters effect on construction quality through monitoring the rolling process and feedback measures.

\section{METHOD OF COMBINATION MODEL}

Combination model is one of the mainstream models of uncertain systems, and has achieved very well effect in many fields such as transportation and tourism. It connects different models by weights, may uses the useful information of models to improve the prediction accuracy, and has the advantages of using valid information of each model and studying the problem from different modeling mechanism and starting point. The main problem of combination model is how to determine the weights of models. The methods of determining the weight coefficient usually are minimum error sum of squares combing weights method and intelligent algorithm combing weights method. In this paper, the minimum error sum of squares linear combination forecasting mode is adopted, which combines the adaptive network-based fuzzy inference system and the improved BP neural network, shown as Figure1.

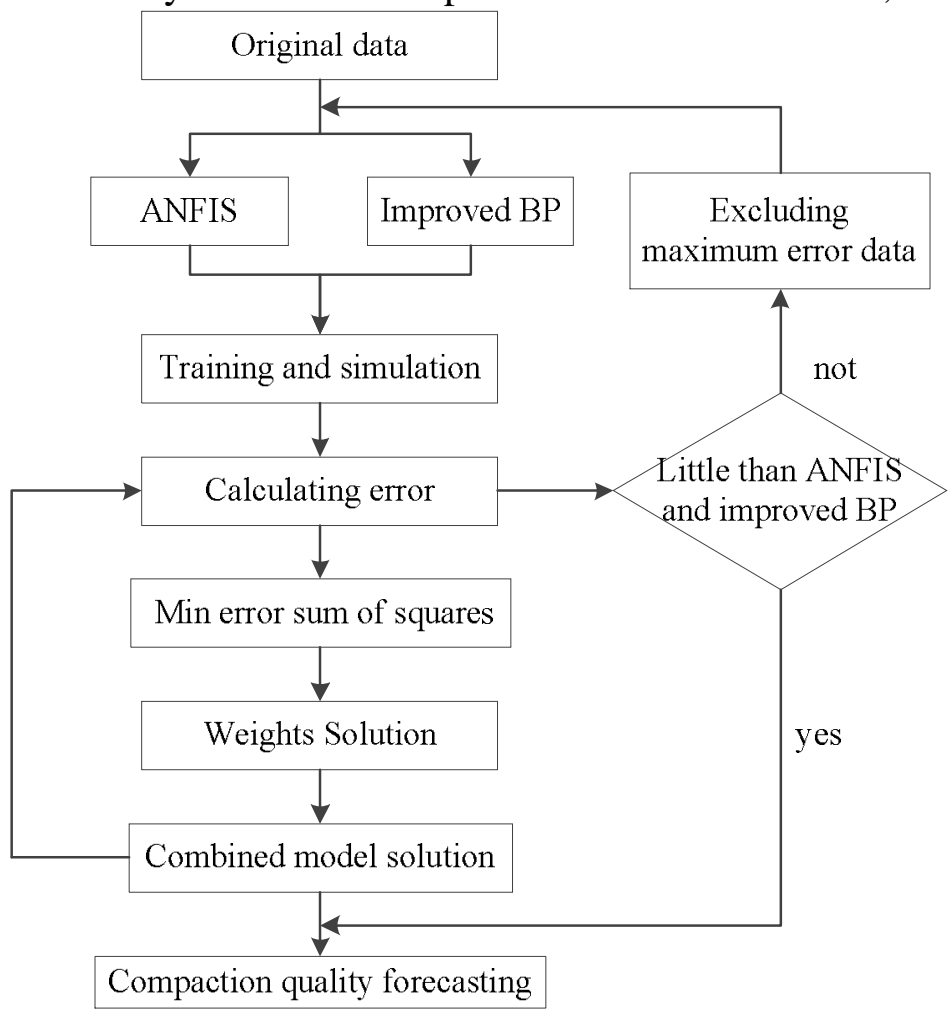

Fig. 1 combination model of rock-fill dam construction quality

The minimum error sum of squares linear combination forecasting mode is an optimal weight method. The basic modeling principle of the combination can be described by the equations as following.

$$
\hat{\mathrm{y}_{k}}=\sum_{i=1}^{n} \omega_{i} y_{i k}
$$




$$
\sum_{i=1}^{n} \omega_{i}=1
$$

In the equations,$y_{i k}$ is the $k t h$ model forecasting value at $k t h$ data $, i=1,2, \ldots, n, k=1,2, \ldots, m . \omega_{i}$ is the weight of $i$ th model.

\section{CASE STUDY}

Hydropower project A is located at downstream of the Lancang River in Yunnan, southwest China. It mainly consists of core rock-fill dam, spillway, water diversion and power generation system. It is the first hydropower project to use real-time monitoring system in whole construction process. Now a core dam unit at EL683.8m is chosen.

Combined the pit test data with the roller monitoring data, matching the space coordinates, the compaction parameters including thickness, rolling passes and average rolling velocity at the text pit can be got. This information makes up of the original data for the following research.

From the 1035 groups of test pit data, the dry density is analyzed, and matched with the space data collecting by real-time monitoring system. At last the compaction thickness and the average velocity data at the test pit is obtained. 775 groups of data is the training sample, and the rest 260 groups is the test sample. After the combination model built, it is adopted to predict the construction quality of the chosen unit.

\section{ANFIS and Improved BP simulation}

Built ANFIS using compaction thickness and the average velocity data as the input, dry density data as the output. For the improved BP, set training epochs as 300 , and training learning rate 0.05 . The optimal number of neurons is determined by stable error searching.

The absolute training error of ANFIS and improved BP is mainly under $0.1 \mathrm{~g} / \mathrm{cm}^{3}$. The error sum of squares of ANFIS is 0.8648 improved BP is 0.9706 . Most of the relative error is less than $5 \%$. These all lead us to the conclusion that the two models have been already stable.

The statistics of Table 1 represents that the max absolute error of ANFIS is $0.1518 \mathrm{~g} / \mathrm{cm}^{3}$, which is smaller than Improved BP $0.1716 \mathrm{~g} / \mathrm{cm}^{3}$, the min absolute error is both 0 , the average absolute error of ASFIS is $0.048 \mathrm{~g} / \mathrm{cm}^{3}$, still smaller than Improved BP $0.053 \mathrm{~g} / \mathrm{cm}^{3}$. In conclusion, ANFIS is a little better than Improved BP.

Table 1 ANFIS and Improved BP training error $\left(\left(\mathrm{g} / \mathrm{cm}^{3}\right)\right)$

\begin{tabular}{cccc}
\hline model & Max absolute error & Min absolute error & Average absolute error \\
\hline ANFIS & 0.1518 & 0 & 0.048 \\
Improved BP & 0.1716 & 0 & 0.053 \\
\hline
\end{tabular}

\section{Combination model solution}

The exiting research provides conditions for combination model research. In the solution error of ANFIS is $e_{1}$, weight $\omega_{1}$, error of Improved BP is $e_{2}$, weight $\omega_{2}$. Finally $W$ is calculated. $W=[0.7457$ 0.2543]. So the combination model is determined. Figure 2 represents the test absolute error. As we can see, most parts of error data of these three models is less than $0.04 \mathrm{~g} / \mathrm{cm}^{3}$, especially the combination model error is at lower level than ANFIS's, which means that the combination model is effective. 


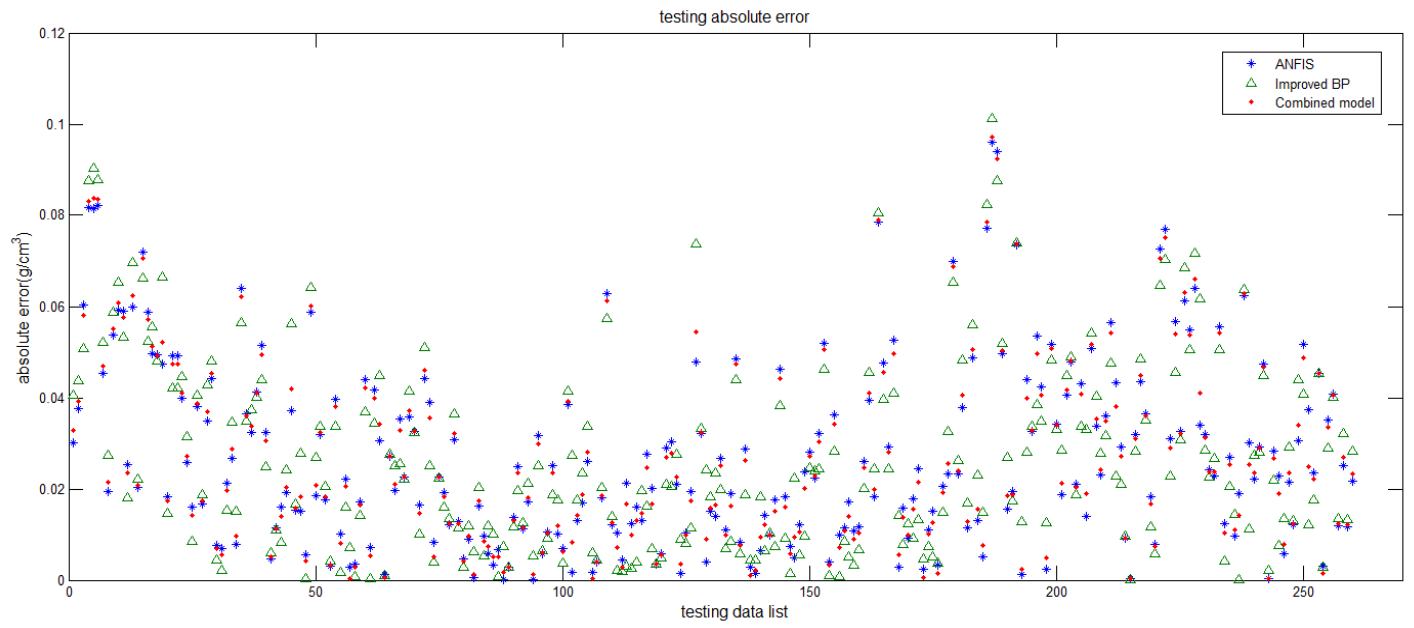

Fig.2 testing absolute error

Table 2 illistrates the detial information of the three kind model. Combination model is better at the max absolute error than ANFIS and Improved BP. The average absolute error of combination model smaller than ANFIS and Improved BP means that the predicting data of combination model is more closer to the original data.

Table2 ANFIS, Improved BP and combination model testing error $\left(\mathrm{g} / \mathrm{cm}^{3} ; \%\right)$

\begin{tabular}{cccc}
\hline model & $\begin{array}{c}\text { Max absolute error } \\
\text { (relative error) }\end{array}$ & $\begin{array}{c}\text { Min absolute error } \\
\text { (relative error) }\end{array}$ & $\begin{array}{c}\text { average absolute error } \\
\text { (average relative error) }\end{array}$ \\
\hline ANFIS & $0.0959(4.975)$ & $0(0)$ & $0.027(1.48)$ \\
Improved BP & $0.101(5.246)$ & $0(0)$ & $0.027(1.45)$ \\
Combination model & $0.0958(4.966)$ & $0(0)$ & $0.020(1.43)$ \\
\hline
\end{tabular}

Meanwhile, the error sum of squares is $Q_{A N F I S}=0.312, Q_{B P}=0.321, Q_{C M}=0.303$. Therefore the combination model is better than the other two models in terms of $Q$. Though there is only a little improvement in accuracy, which may be affect by bad data quality. In other words, the combination model is effective to forecast the compaction quality.

\section{Dam unit compaction quality forecasting}

For the effectiveness of evaluation, the chosen unit is divided into 200 grid. Therefore 200 groups of original data including compaction thickness and roller mean speed are extracted from real-time monitoring system data base. Figure 3 shows the day density forecasting with the combination model.

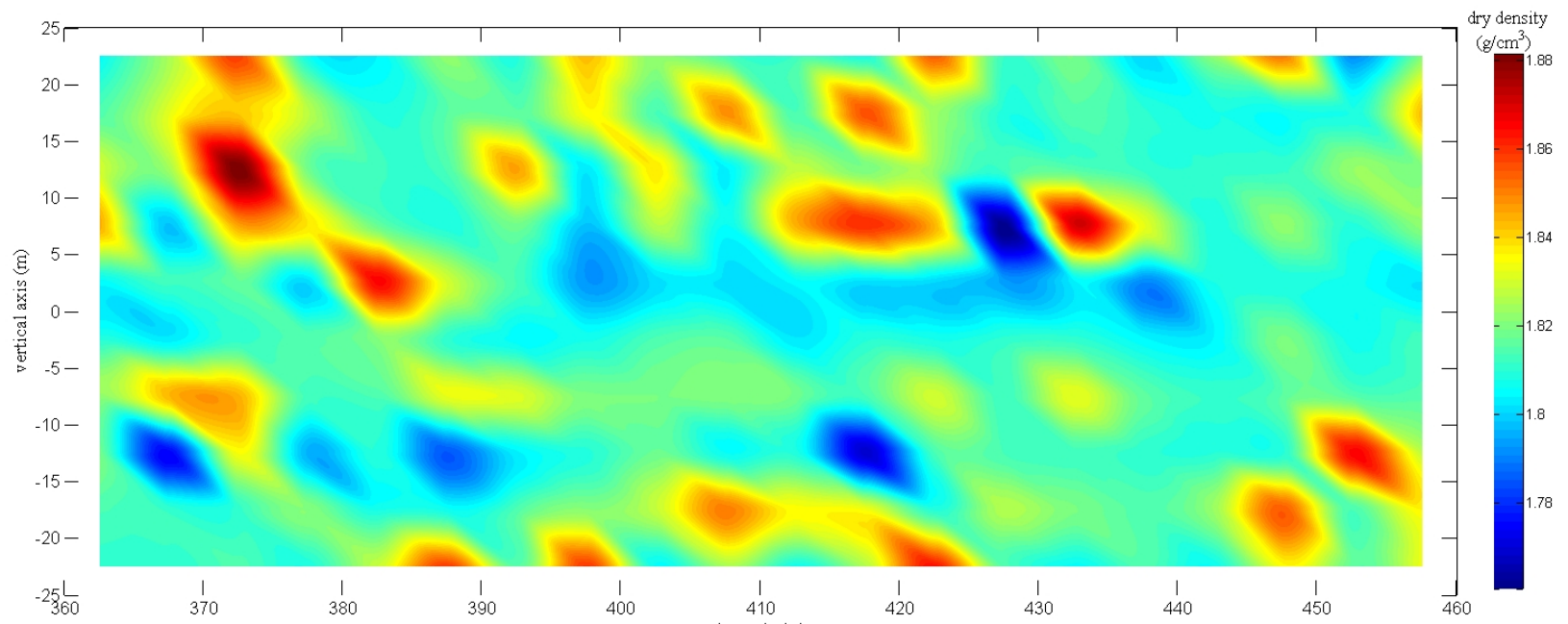

Fig.3 dam surface dry density forecasting 
According to figure3, there is one great day density area, $(372.5,12.5)$, which value is $1.88 \mathrm{~g} / \mathrm{cm}^{3}$, meanwhile, the compaction thickness is $21.7 \mathrm{~cm}$ and the average velocity is $2.386 \mathrm{~km} / \mathrm{h}$. At next grid, $(377.5,12.5)$, the thickness is $21.4 \mathrm{~cm}$, and the velocity is $2.509 \mathrm{~km} / \mathrm{h}$, then the dry density is $1.81 \mathrm{~g} / \mathrm{cm}^{3}$. One can therefore infer that the roller velocity has great influence on the construction quality. On the other hand, it can be seen that the real-time monitoring system plays a very important role in adjusting the construction process.

\section{CONCLUSIONS}

Compared with linear regression model lacking of considering uncertainty between the factors and the research object, ANFIS has stronger reasoning ability. So it can take full account of the uncertainty between construction quality and impact factors.

In the process of quality evaluation, Combination model can join the predicting of different model together organically, and be able to fully reflect the variation of the built system. Meanwhile random error changes with models, combination model can reduce the error. At the point of this paper research, the forecasting accuracy of the combination model is higher than single ANFIS or improved BP. This approach provides a support tool to guide the construction.

An insufficiency in the research is that it does not take uncertainty of material sources into consider in detail. It can be done further research under the condition of sufficient material sources data.

\section{ACKNOWLEDGEMENTS}

This work was financially supported by National Natural Science Foundation of China (51409188), National Natural Science Foundation of China (51409186), and National Natural Science Foundation of China (51439005).

\section{References}

[1] Liu D, Sun J, Zhong D et al. Compaction quality control of earth-rock dam construction using real-time field operation data. Journal of Construction Engineering and Management. Vol. 138(2011), p. 1085-1094.

[2] J. M. BATES and C. W. J. GRANGER . The Combination of Forecasts. Operational Research Society. Vol. 20 (1969), p, 451-468.

[3]Robert R.Andreawis, Amir F. Atiya and Hisham E1-Shishiny. Forecast combinations of computational intelligence and linear models for the NN5 time series forecasting competition. International Journal of Forecasting. Vol. 27(2011), p. 672-688.

[4] Chen Min, Bao Teng-feiland Huang Jia-lee. Combination forecasting model of dam deformation based on FEM and SVM. Water Resources and Power. Vol. 33(2015), p. 87-9, 97.

[5] WANG Rui, ZHONG Denghua, and WU Binping, et al. Compaction quality evaluation of rock-fill dam based on compaction and material parameters. Journal of Hydroelectric Engineering. Vol. 34(2015), p. 146-152.

[6] Zhong Denghua, Liu Donghai and Cui Bo. Real-time compaction quality monitoring of high core rock-fill dam. Science China Technological Science. Vol. 54(2011), p. 1906-1913.

[7] Zhong Denghua, Cui Bo,and Liu Donghai et al. Theoretical research on construction quality real-time monitoring and system integration of core-fill dam. Science in China Series E: Technological Science. Vol. 52(2009), p. 3406-3412. 